\title{
Daily Variations of Photosynthetic Efficiency of Greenhouse Tomato Plants during Winter and Spring
}

\author{
O. Ayari \\ Centre de Recherche en Horticulture, Pavillon de l'Envirotron, Université Laval, Québec, QC, \\ G1K 7P4, Canada
}

\author{
M. Dorais \\ Greenhouse Crops Research Center, Agriculture and Agri-food Canada, Harrow, ON, NOR 1G0, Canada
}

\author{
A. Gosselin ${ }^{1}$ \\ Centre de Recherche en Horticulture, Pavillon de l'Envirotron, Université Laval, Québec, QC, \\ G1K 7P4, Canada
}

\begin{abstract}
AdDitional INDEX wORDs. $\mathrm{CO}_{2}$ enrichment, chlorophyll $a$ fluorescence, hexoses, Lycopersicon esculentum, photosynthetic photon flux, photosynthesis, starch, sucrose
\end{abstract}

\begin{abstract}
Daily and seasonal variations of photosynthetic activity, chlorophyll $a$ (Chl-a) fluorescence and foliar carbohydrate content were studied in situ on greenhouse tomato (Lycopersicon esculentum Mill. 'Trust') plants grown under $\mathrm{CO}_{2}$ enrichment and supplemental lighting. The objective of this study was to assess the effect of seasonal variation of the photosynthetic photon flux $(P P F)$ on photosynthetic efficiency of tomato plants and to determine the presence or absence of photosynthetic down-regulation under greenhouse growing conditions prevailing in northern latitudes. During winter, the fifth and the tenth leaves of tomato plants showed low, constant daily photosynthetic activity suggesting a source limitation under low PPF. In winter, the ratio of variable to maximum Chl- $a$ fluorescence in dark adapted state $\left(F_{v} / F_{m}\right)$ remained constant during the day indicating no photoinhibition occurred. In February, an increase in photosynthetic activity was followed by a decline during March, April, and May accompanied by an increase in sucrose and daily starch concentrations and constant but high hexose level. This accumulation was a long-term response to high $P P F$ and $\mathrm{CO}_{2}$ enrichment which would be caused by a sink limitation. Thus, in spring we observed an in situ downregulation of photosynthesis. The ratio $F_{v} / F_{m}$ decreased in spring compared to winter in response to increasing $P P F$. The daily decline of $F_{v} / F_{m}$ was observed particularly as a midday depression followed by a recovery towards the end of the day. This indicated that tomato leaves were subject to a reversible inhibition in spring. $F_{v} / F_{m}$ was lower in March than in April and May even though PPF was higher in April and May than in March. These results suggest that tomato plants develop an adaptive and protective strategy as $P P F$ increases in spring.
\end{abstract}

Many studies have been conducted on the effect of $\mathrm{CO}_{2}$ enrichment on the physiology, growth, and productivity of plants. Over the short term, a rise in $\mathrm{CO}_{2}$ concentration enhances photosynthesis of $\mathrm{C}_{3}$ plants by stimulating carboxylation of Rubisco (Faria et al., 1996) and carbohydrate synthesis (Kramer, 1981), thereby increasing plant growth (Kimball, 1983). Over the long term, the beneficial effects of elevated $\mathrm{CO}_{2}$ concentration are determined by the balance between carbohydrate production in source leaves and the overall capacity of the plant to use photoassimilates in sink organs (Gunderson and Wullschleger, 1994, van Oosten and Besford, 1994; Yelle et al., 1989a). In sinklimited plants, a loss of photosynthetic efficiency may be caused by a biochemical limitation of inorganic phosphate $\left(\mathrm{P}_{\mathrm{i}}\right)$ and/or Ribulose 1,5-bisphosphate (RuBP) regeneration (Sage, 1990), and eventually by a down-regulation of photosynthesis involving a cascade of reactions that repress the expression of genes, thylakoid proteins, Rubisco, and Rubisco activase proteins (van Oosten and Besford, 1995; Yelle et al., 1989b).

The down-regulation of photosynthesis under high $\mathrm{CO}_{2}$ is increased further by high irradiance and/or long photoperiods (Dorais et al., 1996; Stutte et al., 1996). Under high $\mathrm{CO}_{2}$ concen-

Received for publication 25 Feb. 1999. Accepted for publication 29 Nov. 1999. We thank Les serres du St-Laurent Inc. and Agriculture Quebec for their financial support and G. Samson, S. Yelle, P.A. Dubé, and G. Turcotte for scientific and technical advice. The cost of publishing this paper was defrayed in part by the payment of page charges. Under postal regulations, this paper therefore must be hereby marked advertisement solely to indicate this fact.

${ }^{1}$ Corresponding author; e-mail: andre.gosselin@crh.ulaval.ca. tration and high irradiance, the photosynthetic rate is determined largely by the rate of regeneration of RuBP and the capacity of sucrose synthesis to regenerate $\mathrm{P}_{\mathrm{i}}$ (von Caemmerer and Farquhar, 1981). Low cytoplasmic $P_{i}$ levels may affect the transport of triose-phosphates out of the chloroplast, resulting in high starch levels that are not completely mobilized overnight (Highsmith, 1989; Topa and Cheeseman, 1992).

The significance of these physiological processes has rarely been considered for commercial greenhouse production of tomatoes (Lycopersicon esculentum) which in northern latitudes relies typically on $\mathrm{CO}_{2}$ enrichment as well as supplemental lighting to stimulate growth and productivity (Dorais et al., 1993; Vezina et al., 1991). During the growing season, large variations of incident photosynthetic photon flux $(P P F)$ occur especially in northern latitudes which may affect plant responses to elevated $\mathrm{CO}_{2}$. Little attention has been paid to the daily variations of photosynthetic efficiency of greenhouse tomato plants during the entire period of production from November to May. The objectives of this work were to study daily variations of photosynthetic efficiency of tomato plants under different seasons and to determine the presence or absence of photosynthetic down-regulation in situ under greenhouse conditions prevailing in northern latitudes.

\section{Materials and Methods}

Plant material and growth conditions. Seeds of 'Trust' tomato were sown 15 June 1995 and seedlings transplanted 14 July 1995 on $7.5 \times 20 \times 90 \mathrm{~cm}$ rockwool slabs (Grodan, Agro- 
Dynamics Inc., Milton, Ontario, Canada) in a Venlo glasshouse (Serres du St-Laurent Inc., Portneuf, Quebec, Canada, long. 71.4 $\mathrm{W}$ and lat. $46.7 \mathrm{~N}$ ) at a density of 2.8 plants $/ \mathrm{m}^{2}$. Plants were fertilized with a nutrient solution (electrical conductivity 2.2 $\mathrm{mS} \cdot \mathrm{cm}^{-1}$ ) containing the following nutrients (in $\mathrm{mm}$ ): $12 \mathrm{~N}, 1.6 \mathrm{P}$, 8.5 K, $4 \mathrm{Ca}, 1.8 \mathrm{Mg}, 1.2 \mathrm{Cl}$ and in $(\mu \mathrm{M}) 35.8 \mathrm{Fe}, 7.3 \mathrm{Mn}, 3 \mathrm{Zn}, 3.1$ $\mathrm{Cu}, 46 \mathrm{~B}$, and $0.5 \mathrm{Mo}$ ), using a drip irrigation system. Carbon dioxide enrichment at $1000 \mu \mathrm{mol} \cdot \mathrm{mol}^{-1}$ was achieved during daytime using $\mathrm{CO}_{2}$ produced by the combustion of natural gas. An infrared analyzer (Priva Computer, Beamsville, Ontario, Canada) was used to control $\mathrm{CO}_{2}$ concentration in the greenhouse. Supplemental lighting of $100 \mu \mathrm{mol} \cdot \mathrm{m}^{-2} \cdot \mathrm{s}^{-1}$ photosynthetically active radiation $(P A R)$ was provided by high pressure sodium lamps (HPS, P.L. 780/N 400, P.L. Lighting Systems Canada Inc., Ontario, Canada). The total photoperiod used was progressive, set at $14 \mathrm{~h}$ in September, and then increased progressively to 17 $h$ in December and January. Thereafter, it was shortened progressively from February to April (Iraqi et al., 1997). Lamps were turned off $30 \mathrm{~min}$ before the beginning of the natural dark period, or automatically when natural $P P F$ measured inside the greenhouse at the top of the canopy exceeded $320 \mu \mathrm{mol} \cdot \mathrm{m}^{-2} \cdot \mathrm{s}^{-1}$. Day/ night temperatures were maintained at $19 \pm 2 / 17 \pm 2{ }^{\circ} \mathrm{C}$.

Photosynthetic photon flux. Hourly PPF was monitored each month from November to May. In our present study, we refer to the winter months as November, December, January, and February and to the spring months as March, April, and May. The ambient $P P F$ received by tomato plants is the sum of natural $P P F$ and supplemental lighting provided by HPS lamps (Fig. 1). Light transmission through the glasshouse was estimated at $65 \%$. Seasonal changes in PPF were measured throughout the growing period of tomato plants, beginning in November and ending in May (Fig. 1). Supplemental lighting contributed on average $62 \%$ of the total light available to tomato plants for the winter (November to February) and $15 \%$ on average for the spring (March to April). In winter, $P P F$ did not reach high levels and supplemental lighting continued throughout this period. However, from March PPF increased by midday to $120 \%$ the level measured in February and reached high levels (up to $1200 \mu \mathrm{mol} \cdot \mathrm{m}^{-2} \cdot \mathrm{s}^{-1}$ ) in April and May.

Photosynthetic Measurements. Diurnal measurements of the net photosynthetic rate at ambient light intensity $\left(\mathrm{P}_{\mathrm{N}}\right)$ were performed under incident $P P F$ received by tomato plants. Measurements of $\mathrm{CO}_{2}$ assimilation rate were performed at $4 \mathrm{~h}$ intervals, on the fifth and the tenth developed leaves from the apex of tomato plants, using a portable photosynthesis system (LI-6200, LI-COR, Inc., Lincoln, Neb.). To determine the maximum photosynthetic rate at saturating light intensity $\left(\mathrm{P}_{\max }\right)$, a red light emitting diode (LED) supplying a $P P F$ of $800 \mu \mathrm{mol} \cdot \mathrm{m}^{-2} \cdot \mathrm{s}^{-1}$ was used. Photosynthetic measurements were taken every $4 \mathrm{~h}$ after artificial lighting was turned on up to the beginning of the dark period. Photosynthetic measurements were repeated monthly from November 1995 to May 1996 on the fifth and the tenth leaves from a sample of 10 tomato plants chosen randomly in the greenhouse. Average of 10 measurements was calculated as well as the SE.

Chl- $a$ Fluorescence Measurements. Chlorophyll $a$ (Chl- $a)$ fluorescence induction kinetics were determined on 10 samples of fifth and tenth leaves each of which were used for photosynthetic measurements. Fluorescence measurements were made $1 \mathrm{~h}$ after the lamps were turned on, and every $4 \mathrm{~h}$ thereafter throughout the 24-h period. Chl- $a$ fluorescence was measured during a 1 $\mathrm{s}$ flash of bright red light $\left(3250 \mu \mathrm{mol} \cdot \mathrm{m}^{-2} \cdot \mathrm{s}^{-1}\right.$ centered at $\left.650 \mathrm{~nm}\right)$ using a plant efficiency analyzer (PEA, Hansatech Ltd., Norfolk,
United Kingdom) as described by Strasser et al. (1995). Measurements were performed after a 20 min dark acclimation period. The minimal $\left(\mathrm{F}_{\mathrm{o}}\right)$ and the maximal $\left(\mathrm{F}_{\mathrm{m}}\right)$ unquenched yields of Chl$a$ fluorescence were determined in dark acclimated leaves. From these fluorescence levels, the maximum quantum yield of photosystem II (PSII) photochemistry was estimated by the ratio of variable to maximum fluorescence in dark adapted leaves $F_{v} / F_{m}$ (where $F_{v}=F_{m}-F_{o}$ ). Measurements were made on the fifth and the tenth leaves from a sample of 10 tomato plants chosen randomly in the greenhouse. Average of 10 measurements was calculated as well as the SE.

Carbohydrate analysis. Soluble sugar (glucose, fructose, and sucrose) and starch concentrations were analyzed as described by Ozbun et al. (1973) on the same fifth and tenth leaves used for photosynthetic and Chl- $a$ fluorescence measurements (10 samples each). They were collected at 4-h intervals over a 24$h$ period, frozen immediately in liquid nitrogen $\left(\mathrm{N}_{2}\right)$ and stored at $-80{ }^{\circ} \mathrm{C}$ until use. Leaves were ground in liquid $\mathrm{N}_{2}$ with a mortar and pestle. Glucose, fructose, and sucrose were determined using high performance liquid chromatography (HPLC, Waters Co. Milford, Mass.; Sugar-PAK column $6.5 \times 300 \mathrm{~mm}$ using Waters $600 \mathrm{E}$ pump). Sugar concentrations were expressed as $\mathrm{mg} \cdot \mathrm{g}^{-1}$ fresh weight $(\mathrm{FW})$. To digest the starch on the pellets, amyloglucosidase (EC 3.2.1.3), supplied by Sigma Chemical Co. (St. Louis, Mo.), was added to samples and incubated in a water bath at 50 to $55^{\circ} \mathrm{C}$ for $3 \mathrm{~h}$. Glucose content was determined using the YSI 7200 (Yellow Springs Inc., Ohio.). The final starch concentration per sample was expressed as $\mathrm{mg}$ glucose/g FW. Leaf sampling for carbohydrate analyses was conducted $1 \mathrm{~h}$ after the lamps were turned on, and every $4 \mathrm{~h}$ thereafter for $24 \mathrm{~h}$. Analysis were made on the fifth and the tenth leaves from a sample of 10 tomato plants chosen randomly in the greenhouse. Average of 10 measurements was calculated as well as the SE.

\section{Results}

Seasonal CHANGES OF PHOTOSYNTHESIS. For each month from November to May, $\mathrm{P}_{\mathrm{N}}$ were measured on the fifth and the tenth leaves at regular intervals during a sunny day (Fig. 2). From November to January, $\mathrm{P}_{\mathrm{N}}$ values of both the fifth and the tenth leaves were relatively low (4 to $6 \mu \mathrm{mol} \cdot \mathrm{m}^{-2} \cdot \mathrm{s}^{-1}$ ) and did not show significant variations during the day. From February to April, maximum $\mathrm{P}_{\mathrm{N}}$ was reached at the highest $P P F$ recorded during the day. In contrast, in May $\mathrm{P}_{\mathrm{N}}$ reached its maximum after only $4 \mathrm{~h}$ of light period (0900 HR), whereas maximum PPF was reached $4 \mathrm{~h}$ after $0900 \mathrm{HR}$ (at $1300 \mathrm{HR}$ ).

The $\mathrm{P}_{\max }$ of the fifth and the tenth leaves were constant from November to January. From February to May, large daily differences of $\mathrm{P}_{\max }$ were observed despite the same saturating light (Fig. 3). But in February, $\mathrm{P}_{\max }$ reached $17 \mu \mathrm{mol} \cdot \mathrm{m}^{-2} \cdot \mathrm{s}^{-1}$ and 10 $\mu \mathrm{mol} \cdot \mathrm{m}^{-2} \cdot \mathrm{s}^{-1}$ for the fifth and the tenth leaves, respectively, after 8 h of light $(1000 \mathrm{HR})$. Maximum $\mathrm{P}_{\max }$ was reached at $1100 \mathrm{HR}$ in March and then earlier in April and May (0900 HR) before $P P F$ reached its maximum. The increase in $P P F$ during these months did not increase $\mathrm{P}_{\max }$ proportionally, since $\mathrm{P}_{\max }$ increased significantly from January to February, then decreased from March, since $\mathrm{P}_{\max }$ was lower in spring than in February despite higher $P P F$.

SEasonal VARiations of ChL- $\boldsymbol{a}$ FLUORESCENCE. Daily patterns of variation of the maximal photochemical efficiency of PSII estimated by the Chl- $a$ fluorescence ratio $\mathrm{F}_{\mathrm{v}} / \mathrm{F}_{\mathrm{m}}$ were studied each month. The ratio $\mathrm{F}_{\mathrm{v}} / \mathrm{F}_{\mathrm{m}}$, remained constant (0.82 to 0.86$)$ during the daily cycle of November, December, January, and February, 
for both the fifth or the tenth leaves (Fig. 4). However, in spring the ratio $F_{v} / F_{m}$ decreased at midday especially for the fifth leaves where $F_{v} / F_{m}$ reached the lowest values in March (0.77), and recovered in the evening. In April and May, $F_{v} / F_{m}$ showed a similar pattern during midday but did not reach as low values as recorded in March, although PPF was higher in April and May than in March.

Seasonal changes of carbohydrate. Sucrose content of tomato leaves was significantly lower in winter than in spring months (Fig. 5). Leaf sucrose concentrations were related to seasonal and daily changes of $P P F$. We also observed higher initial concentrations of sucrose at the beginning of the diurnal period in spring than in winter. Leaf hexose content was fairly constant during the day for all months (Fig. 6). However, in spring, hexose content in leaves increased up to 4 fold compared to winter months. Starch concentration in leaves behaved differently over the course of the day in winter compared to spring (Fig. 7). Starch concentration remained constant during the day in November to February. However, there was a seasonal increase

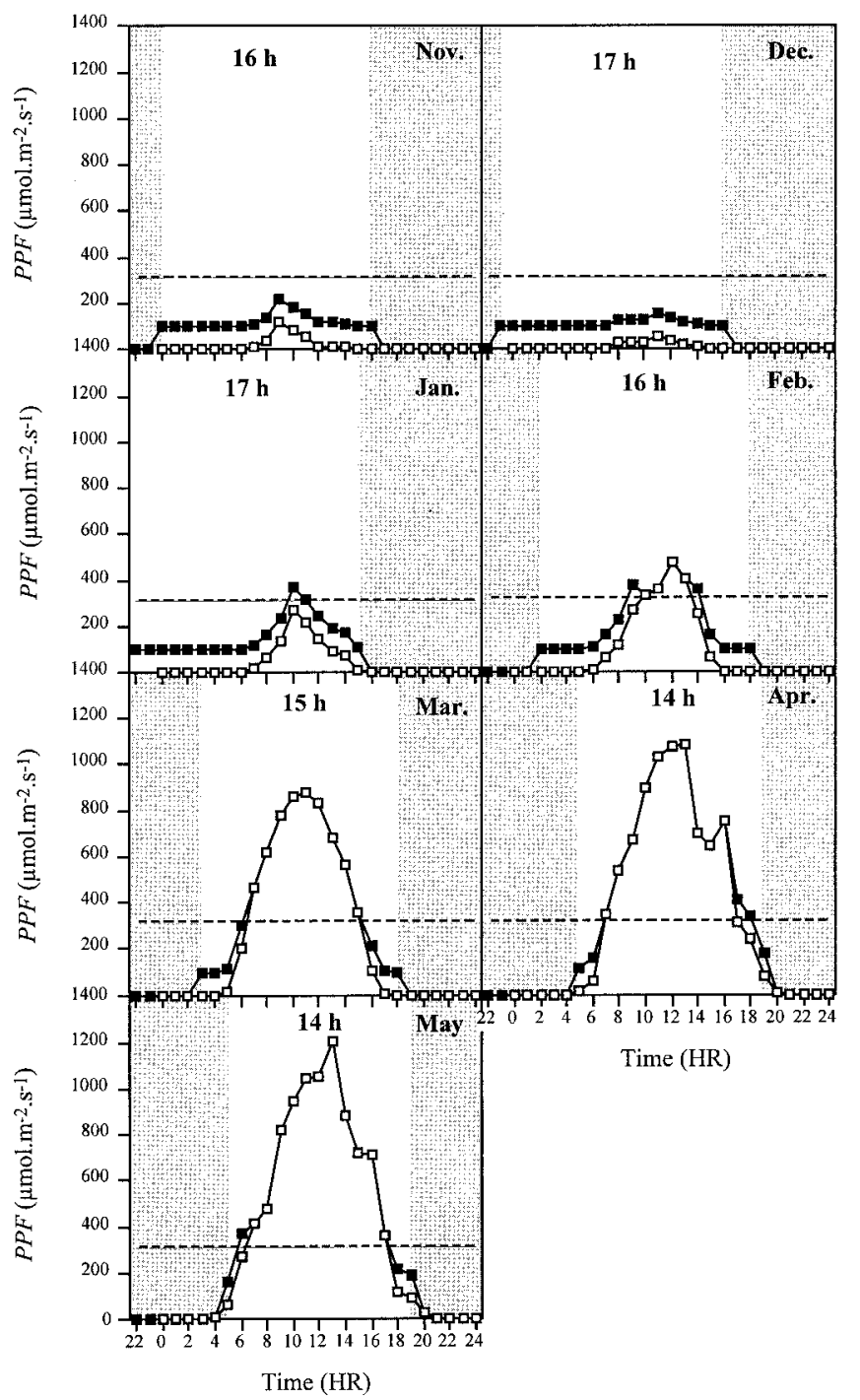

Fig. 1. Hourly variations of total $P P F$ (closed squares) received by tomato plants. Values are the sum of natural $P P F$ (open squares) plus artificial $P P F$ provided by HPS lamps $\left(100 \mu \mathrm{mol} \cdot \mathrm{m}^{-2} \cdot \mathrm{s}^{-1}\right)$, from November to April. Nonshaded areas represent the total photoperiods. The dashed horizontal line represents the 320 $\mu \mathrm{mol} \cdot \mathrm{m}^{-2} \cdot \mathrm{s}^{-1}$.level at which lamps were automatically turned off. in leaf starch content in spring, and initial content of leaves in starch at the beginning of the photoperiod in spring was greater than in winter. From March, plants exposed to high PPF accumulated starch during the light period.

\section{Discussion}

Many researchers have studied the effects of $\mathrm{CO}_{2}$ enrichment, supplemental lighting, and photoperiod on growth, yield, development, and physiology of greenhouse crops. However, little work has been done on the influence of seasonal variations of light on tomato plants grown under supplemental lighting and $\mathrm{CO}_{2}$ enrichment in terms of photosynthetic efficiency and carbohydrate leaf content. The present research demonstrates the relationship between seasonal variations of $P P F$ on photosynthetic parameters $\left(\mathrm{P}_{\mathrm{N}}, \mathrm{P}_{\max }\right.$, and Chl- $a$ fluorescence $)$ and leaf carbohydrate concentration.

From November to January, photosynthetic activity was lim-

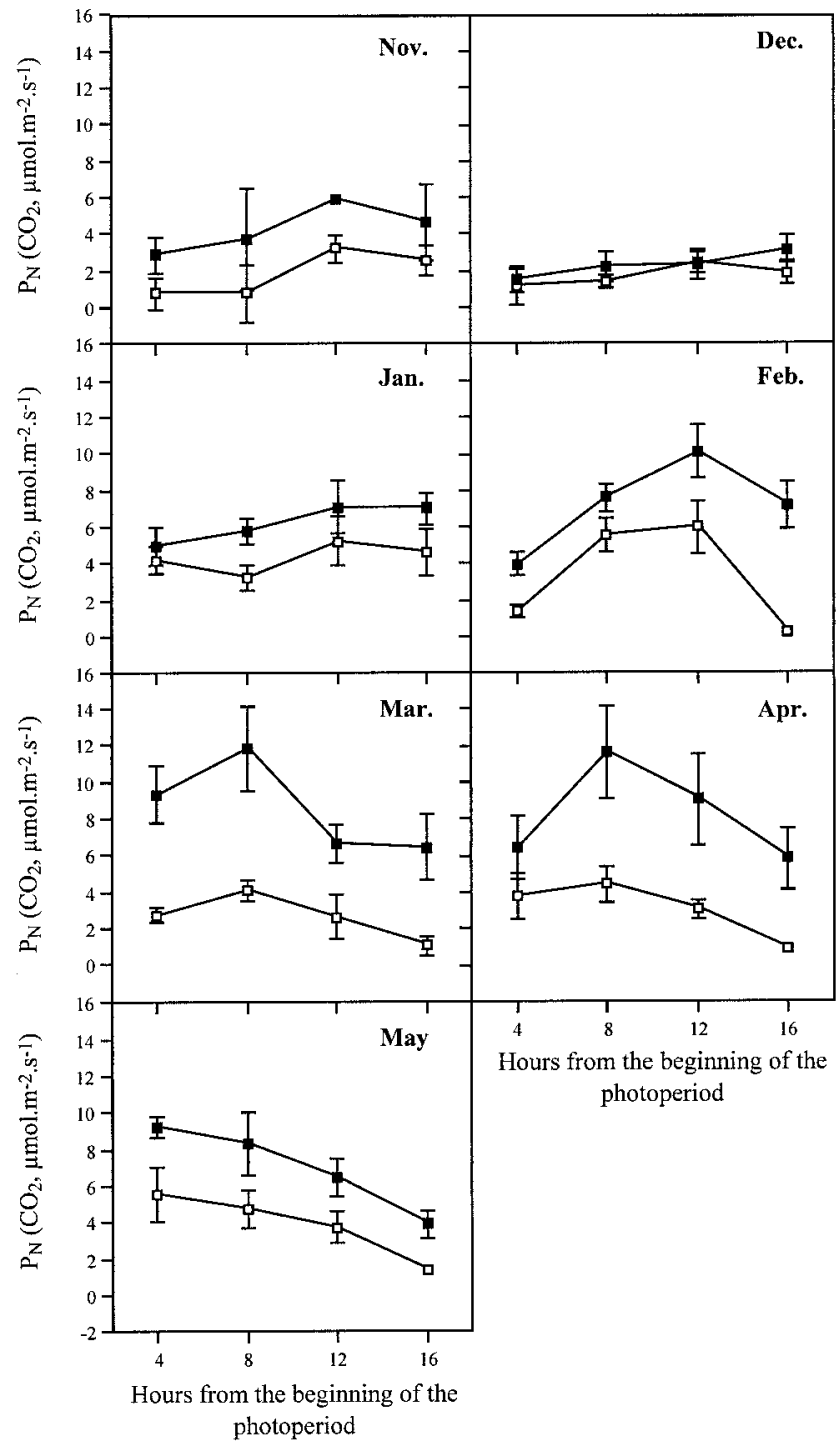

Fig. 2. Diurnal variations of $P_{N}$ of the fifth (closed squares) and the tenth (open squares) leaves of tomato plants from November to May. Measurements were taken four times a day at 4-h intervals, starting $1 \mathrm{~h}$ after the beginning of the photoperiod. Data are the mean values of 10 independent measurements $\pm \mathrm{SE}$. In some cases the standard error bar is obscured by the symbol. 
ited by the low natural $P P F$ received by plants (Figs. 2 and 3). In winter, artificial lighting contributed significantly to the total $P P F$ received by the canopy (Fig. 1), so photosynthetic activity was constant during the day since artificial $P P F$ irradiance was unchanged. Under northern latitudes, use of supplemental lighting in winter is beneficial for greenhouse tomato plants as shown previously (Demers et al., 1998; Dorais et al., 1993; Vezina et al., 1991). In our present study, the contribution of supplemental lighting to the total $P P F$ received by plants was higher in winter (62\% in average) than in spring (15\% in average). Although supplemental lighting was used, photosynthetic activity of tomato plants remained low suggesting a source limitation during winter when plants were subject to low PPF. Sage (1990) suggested that at subsaturating irradiance, as prevailed during winter in the present study, when electron transport limits photosynthesis, the activity of Rubisco is down-regulated to balance the limiting rate of RuBP regeneration.

In February, as natural $P P F$ increased, the contribution of

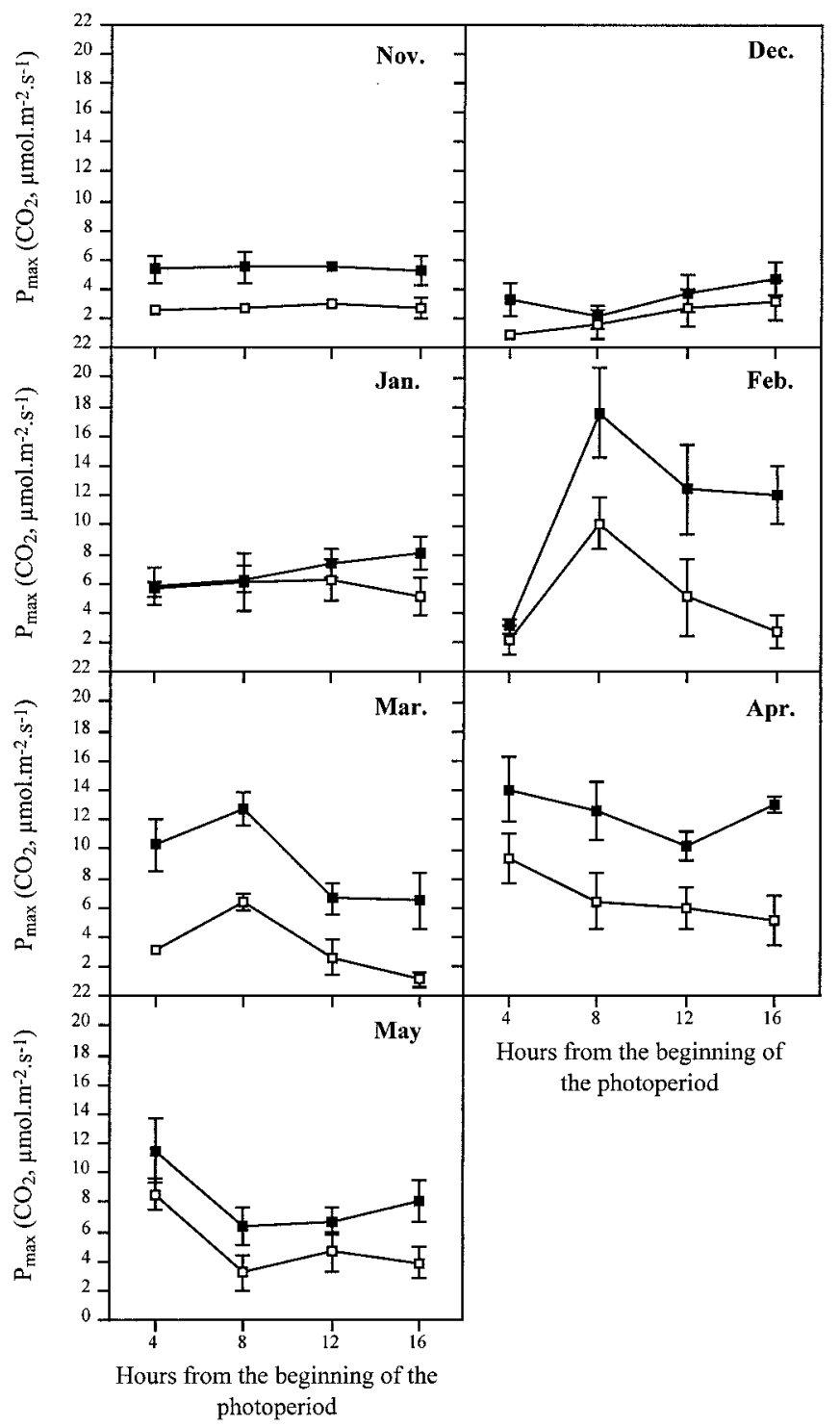

Fig. 3. Diurnal variations of $P_{\max }$ of the fifth (closed squares) and the tenth (open squares) leaves of tomato plants from November to May. Measurements were taken four times a day at 4-h intervals, starting $1 \mathrm{~h}$ after the beginning of the photoperiod. Data are the mean values of 10 independent measurements \pm SE. In some cases the standard error bar is obscured by the symbol. supplemental lighting decreased and tomato plants exhibited a higher $\mathrm{P}_{\mathrm{N}}$ and $\mathrm{P}_{\max }$ compared to November to January. In contrast, from March to May, both $\mathrm{P}_{\mathrm{N}}$ and $\mathrm{P}_{\max }$ decreased although $P P F$ increased. Under high irradiance and $\mathrm{CO}_{2}$-enriched conditions, our photosynthetic data showed a decline from March until May. This is consistent with acclimation of photosynthesis observed frequently under $\mathrm{CO}_{2}$-enriched atmosphere, where an initial stimulation of photosynthesis is followed by a decrease (Bowes, 1991) that usually involves a decline of Rubisco activity (Stitt, 1991; van Oosten and Besford, 1995; Yelle et al., 1989b).

Our data showed that the tenth tomato leaves had always lower $\mathrm{P}_{\mathrm{N}}$ and $\mathrm{P}_{\max }$ versus the fifth leaves. Morphologically, the fifth leaf represents $45 \%$ to $60 \%$ of its final area (data not presented). On tomato plants the light-saturated rate of photosynthesis reached a maximum at $60 \%$ leaf expansion for plants in all growth conditions (from $\mathrm{CO}_{2}$ levels of 350 to $1400 \mu \mathrm{mol} \cdot \mathrm{mol}^{-1}$ ) and then declined to half or less of the maximum value when the leaf was mature (van Oosten and Besford, 1995).

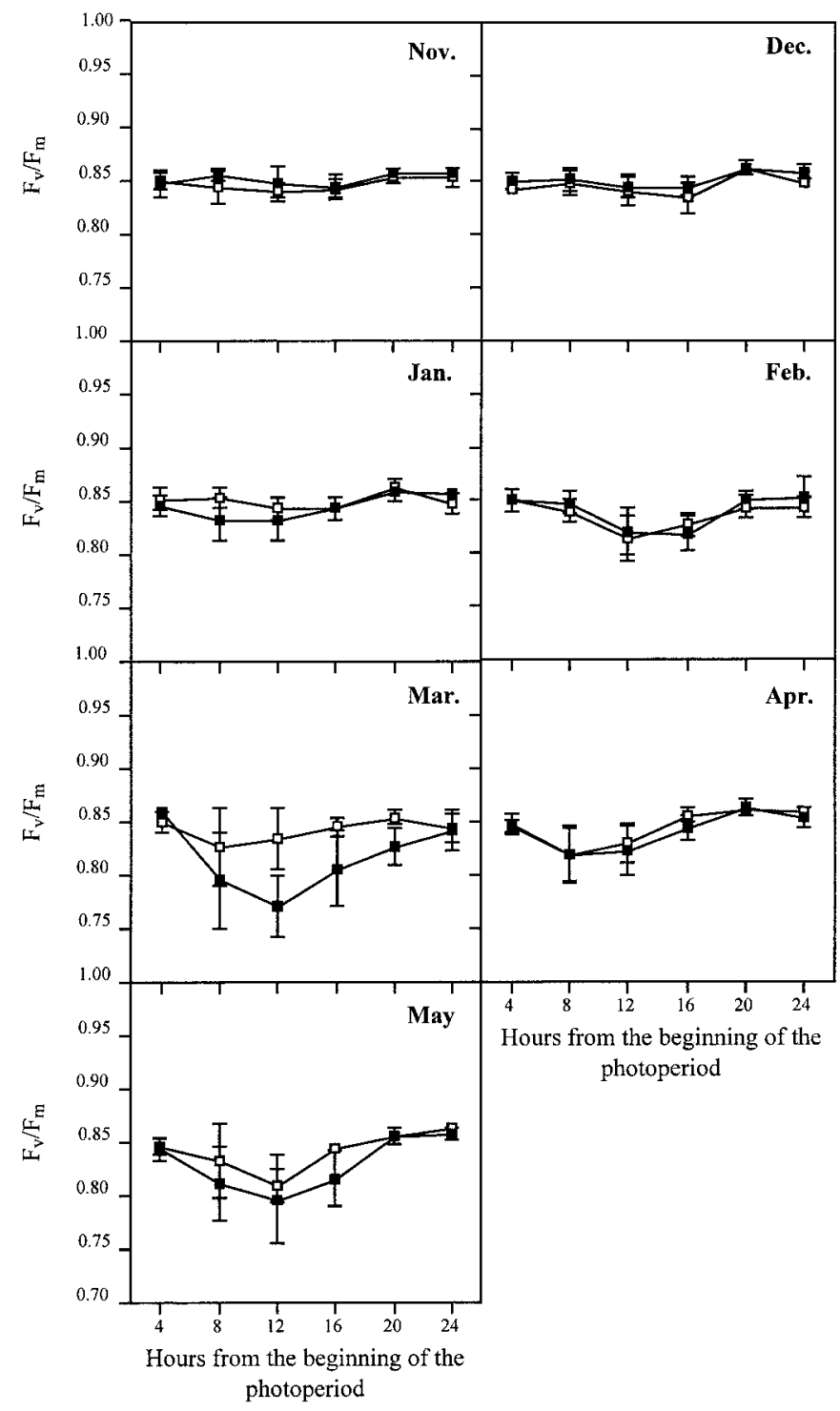

Fig. 4. Daily variations of $F_{v} / F_{m}$ of the fifth (closed squares) and the tenth (open squares) leaves of tomato plants from November to May. Measurements were taken six times a day at 4-h intervals, starting $1 \mathrm{~h}$ after the beginning of the photoperiod. Data are the mean values of 10 independent measurements \pm SE. In some cases the standard error bar is obscured by the symbol. 
Under winter conditions, the $F_{v} / F_{m}$ ratios of the fifth and the tenth leaves were constant and similar during the photoperiod (Fig. 4). $F_{v} / F_{m}$ ratio is closely related to maximum PSII quantum yield (Butler, 1977) and correlated to the maximum photosynthesis quantum yield (Demmig and Björkman, 1987). The $F_{v} / F_{m}$ ratio constitutes a diagnostic probe for photoinhibition (Demmig and Björkman, 1987). Quenching, resulting from photoinhibition, is often expressed as a decrease in the ratio $\mathrm{F}_{\mathrm{v}} / \mathrm{F}_{\mathrm{m}}$ recorded when a dark period of 15 to $20 \mathrm{~min}$ follows a high light exposure (Krause and Weis, 1991). In winter, $F_{v} / F_{m}$ showed a constant pattern suggesting that no photoinhibition of photosynthesis occurred during winter.

The increase of $P P F$ in spring was accompanied by changes in Chl- $a$ fluorescence parameters. The $\mathrm{F}_{\mathrm{v}} / \mathrm{F}_{\mathrm{m}}$ ratio decreased and reached lower midday values than those observed in winter. In spring, the $\mathrm{F}_{\mathrm{v}} / \mathrm{F}_{\mathrm{m}}$ response to seasonal changes of PPF suggests that tomato leaves were subject to photoinhibition (Powles, 1984). However, this photoinhibition was reversible as $F_{v} / F_{m}$

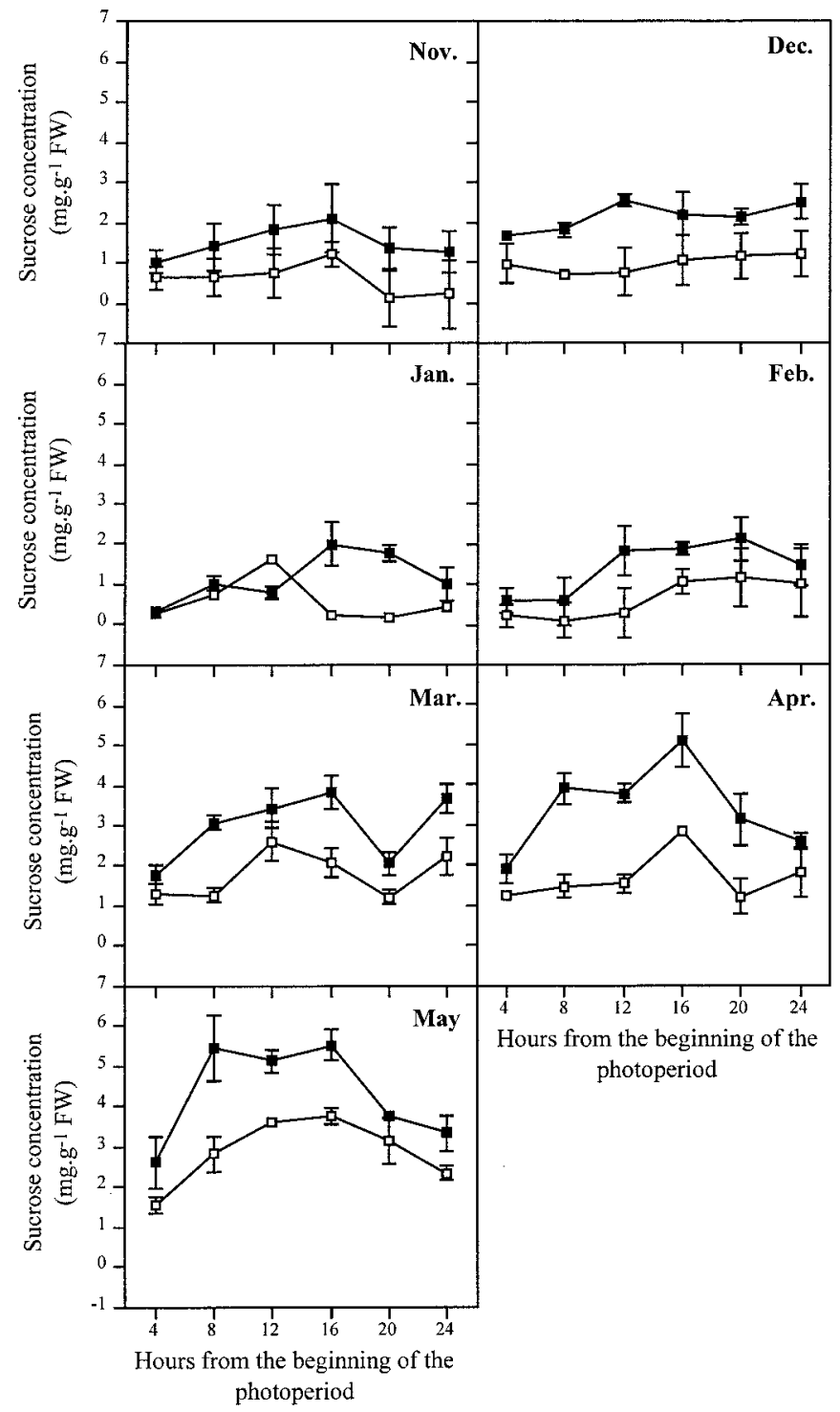

Fig. 5. Daily variations of sucrose concentration on the fifth (closed squares) and the tenth (open squares) leaves of tomato plants from November to May. Samples were taken six times a day at 4-h intervals, starting $1 \mathrm{~h}$ after the beginning of the photoperiod. Data are the mean values of 10 independent measurements \pm SE. In some cases the standard error bar is obscured by the symbol. recovered at the end of the day possibly representing a protective strategy from excessive light (Gilmore, 1997), so reducing the probability of permanent photooxidative damage. This protection strategy and adaptation towards high irradiance developed progressively throughout the season. In April and May, $\mathrm{F}_{\mathrm{v}} / \mathrm{F}_{\mathrm{m}}$ was higher than that observed in March, although $P P F$ was higher in April and May than in March.

Our $\mathrm{P}_{\mathrm{N}}$ and $\mathrm{P}_{\max }$ data showed a decrease in photosynthetic capacity of leaves in spring (Figs. 2 and 3 ) resulting in part from photoinhibition. Recently, photoinhibition and reduced photosynthetic efficiency were measured on cork oak (Quercus suber L.) (García-Plazaola et al., 1997), sugarcane [Miscanthus floridulus (Labill.) Warb.] (Kao et al., 1998), and tomato (Lycopersicon hirsutum Dunal) (Jung et al., 1998). In the present study, we noted that the tenth leaves were less affected by photoinhibition than fifth leaves, as the tenth leaves had higher $\mathrm{F}_{\mathrm{v}} / \mathrm{F}_{\mathrm{m}}$. Baker and Bowyer (1994) reported that under high $P P F$, the upper but not the lower leaves in the canopy became photoinhibited.

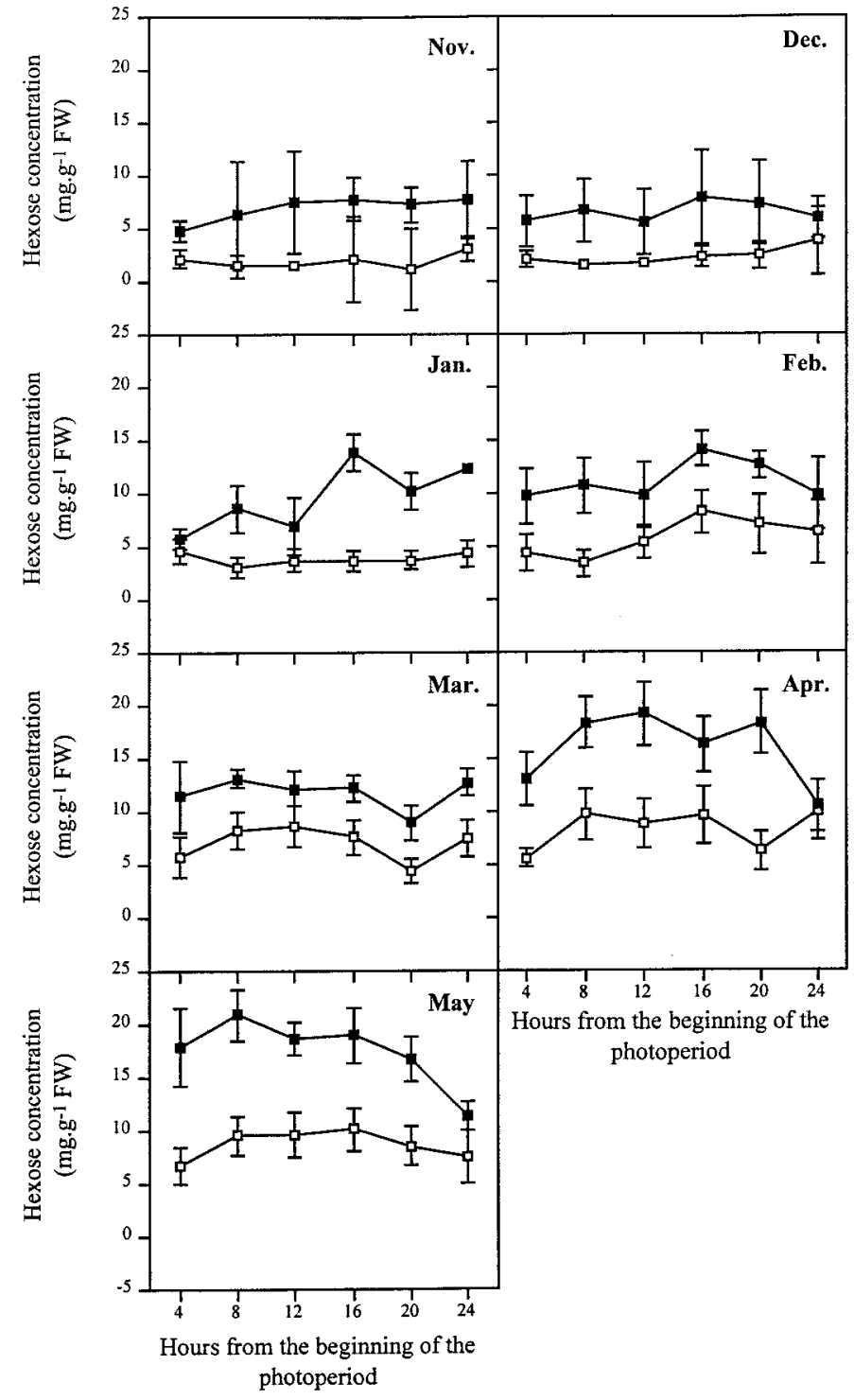

Fig. 6. Daily variations of hexose concentration on the fifth (closed squares) and the tenth (open squares) leaves of tomato plants from November to May. Samples were taken six times a day at 4-h intervals, starting $1 \mathrm{~h}$ after the beginning of the photoperiod. Data are the mean values of 10 independent measurements \pm SE. In some cases the standard error bar is obscured by the symbol. 
During winter months, when tomato plants were under low $P P F$ and $\mathrm{CO}_{2}$ enriched atmosphere, we observed low and constant daily concentrations of sucrose (Fig. 5), hexoses (Fig. 6), and starch (Fig. 7). Sage (1990) reported that sucrose synthesis was regulated downward following reductions in irradiance due in part to changes in the level of fructose-2,6-bisphosphate and in some cases by modulation of the activity of sucrose phosphate synthase. In spring, our results showed an increase in daily sucrose and starch contents and an increase up to 4 fold of hexose concentrations in spite of its constant pattern at the same period where we observed a decrease in photosynthetic activity (Figs. 2 and 3). Under high irradiance and high $\mathrm{CO}_{2}$ concentrations, as prevailed in our experiment during spring, the decline of photosynthetic efficiency of plants was caused by an accumulation of starch (Bowes, 1991; Galtier et al., 1995; Stitt, 1991; Yelle et al., 1989a). Over the long term, growth under $\mathrm{CO}_{2}$ enrichment leads to a change in the sink-source balance of the plant. Van Oosten

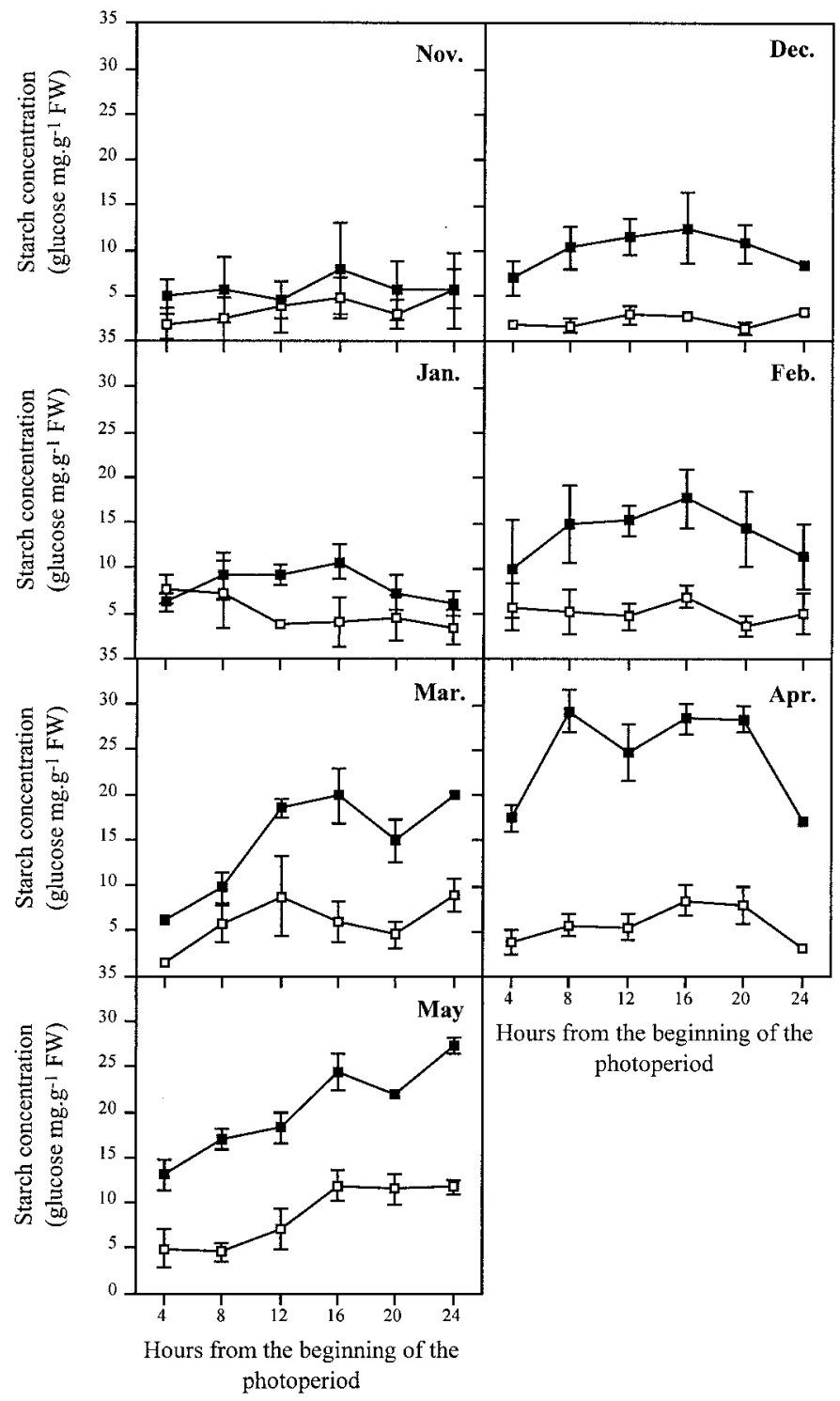

Fig. 7. Daily variations of starch concentration on the fifth (closed squares) and the tenth (open squares) leaves of tomato plants from November to May. Samples were taken six times a day at 4-h intervals, starting $1 \mathrm{~h}$ after the beginning of the photoperiod. Data are the mean values of 10 independent measurements $\pm \mathrm{SE}$. In some cases the standard error bar is obscured by the symbol. and Besford (1994) suggested that accumulation of carbohydrate occurred progressively as a result of an insufficient sink strength. Thus, this suggests that in spring a sink limitation results from high levels of $\mathrm{CO}_{2}$ and light. So, carbohydrate accumulates in the source leaves as the rate of photosynthesis exceeds the capacity of the sinks to utilize the photosynthate for growth (Stitt, 1991). A limitation of the transport capacity of photoassimilates from sources to sinks can further increase accumulation of carbohydrate in leaves and then can be at the origin of changes in gene expression enzyme activity and protein content leading consequently to a negative feedback on the assimilation rate (Krapp et al., 1993).

At high $\mathrm{CO}_{2}$ and saturating light, photosynthesis is limited by the rate of regeneration of the substrate of carboxylation, RuBP. The latter is determined by the rate of electron transport that provides the NADP and ATP to drive the Calvin cycle. ATP synthesis in turn, may be restricted by the availability of $\mathrm{P}_{\mathrm{i}}$ (Galtier et al., 1995). When light and $\mathrm{CO}_{2}$ are not limiting, photosynthesis rate is determined by the capacity of sucrose synthesis to generate $\mathrm{P}_{\mathrm{i}}(\mathrm{Stitt}, 1991)$. The decrease of $\mathrm{P}_{\mathrm{i}}$ concentration in cytoplasm and stroma induces a reduction of triosesphosphates output from the chloroplast, leading consequently to starch accumulation (Dorais et al., 1996; Faria et al., 1996; Sawada et al., 1989; Yelle et al., 1989a). This would suggest that decline of photosynthesis of tomato plants during spring was caused by carbohydrate accumulation that could induce changes in gene expression of Rubisco and its activity, leading consequently to the down-regulation of photosynthesis.

In conclusion, during winter, low photosynthetic rates were observed suggesting source limitation of tomato plants under low $P P F$ and high $\mathrm{CO}_{2}$ concentrations. High $\mathrm{F}_{\mathrm{v}} / \mathrm{F}_{\mathrm{m}}$ ratio values indicated that during winter tomato plants were not subject to photoinhibition. Corresponding to low photosynthetic rates, low carbohydrate contents were found both in the fifth and the tenth leaves. In contrast to November, December, and January, we measured an increase in photosynthetic activity during February followed by a decline in March, April, and May. In spring, we measured daily accumulation of sucrose and starch and high constant level of hexoses as a long-term response to high PPF levels and high $\mathrm{CO}_{2}$ enriched atmosphere. This accumulation of carbohydrate was suggested to be caused by sink strength limitation (van Oosten and Besford, 1994). So, we conclude that under greenhouse conditions in northern latitudes, photosynthetic downregulation in situ caused by an accumulation of carbohydrate in leaves occurred in spring but not in winter.

\section{Literature Cited}

Baker, N.R. and J.R. Bowyer. 1994. Photoinhibition of photosynthesis: From molecular mechanisms to the field. Bios Scientific Publishers, Oxford, United Kingdom.

Bowes, G. 1991. Growth at elevated $\mathrm{CO}_{2}$ : Photosynthetic responses mediated through Rubisco. Plant Cell Environ. 14:795-806.

Butler, W.L. 1977. Chlorophyll fluorescence as a probe for electron transfer and energy transfer, p. 149-167. In: A. Trebst and M. Avron (eds.). Encyclopedia of plant physiology. vol. 3. Springer Verlag, Berlin. Demers, D.A., M. Dorais, H.C. Wien, and A. Gosselin. 1998. Effects of supplemental light duration on greenhouse tomato (Lycopersicon esculentum Mill.) plants and fruit yields. Scientia Hort. 74:295-306.

Demmig, B. and O. Björkman. 1987. Comparison of the effect of excessive light fluorescence $(77 \mathrm{~K})$ and photon yield of $\mathrm{O}_{2}$ evolution in leaves of higher plants. Planta 171:171-184.

Dorais, M., J. Charbonneau, and A. Gosselin. 1993. Gas exchange in greenhouse tomatoes grown under supplemental light. Can. J. Plant 
Sci. 73:577-585.

Dorais, M., S. Yelle, and A. Gosselin. 1996. Influence of extended photoperiod on photosynthate partitioning and export in tomato and pepper plants. N.Z. J. Crop Hort. Sci. 24:29-37.

Faria, T., D. Wilkins, R.T. Besford, M. Vaz, J.S. Pereira, and M.M. Chaves. 1996. Growth at elevated $\mathrm{CO}_{2}$ leads to down-regulation of photosynthesis and altered response to high temperature in Quercus suber L. seedlings. J. Expt. Bot. 47:1755-1761.

Galtier, N., C.H. Foyer, E. Murchie, R. Alred, P. Quick, T.A. Voelker, C. Thépenier, G. Lascève, and T. Betsche. 1995. Effects of light and atmospheric carbon dioxide enrichment on photosynthesis and carbon partitioning in the leaves of tomato (Lycopersicon esculentum L.) plants over-expressing sucrose phosphate synthase. J. Expt. Bot. 46:1335-1344.

García-Plazaola, J.I., T. Faria, J. Abadía, A. Abadía, M.M. Chaves, and J.S. Pereira. 1997. Seasonal changes in xanthophyll composition and photosynthesis of cork oak (Quercus suber L.) leaves under mediterranean climate. J. Expt. Bot. 48:1667-1674.

Gilmore, A.M. 1997. Mechanistic aspects of xanthophyll cycle-dependent photoprotection in higher plants chloroplasts and leaves. Physiol. Plant. 99:197-209.

Gunderson, C.A. and S.D. Wullschleger. 1994. Photosynthetic acclimation in trees to rising $\mathrm{CO}_{2}$ : A broader perspective. Photosyn. Res. 39:369-388.

Highsmith, M.T. 1989. A model of starch partitioning in mature soybean leaves. Plant Physiol. 89:12 (abstr.).

Iraqi, D., L. Gauthier, M. Dorais, and A. Gosselin. 1997. Influence du déficit de pression de vapeur et de la photopériode sur la croissance, la productivité et la composition minérale de la tomate de serre. Can. J. Plant Sci. 77:267-272.

Jung, S., K.L. Steffen, and H.J. Lee. 1998. Comparative photoinhibition of a high and low altitude ecotype of tomato (Lycopersicon hirsutum) to chilling stress under high and low light conditions. Plant Sci. 134:69-77.

Kao, W.Y., T.T. Tsai, and W.H. Chen. 1998. Response of photosynthetic gas exchange and chlorophyll $a$ fluorescence of Miscanthus floridulus (Labill.) Warb. to temperature and irradiance. J. Plant Physiol. 152:407412.

Kimball, B.A. 1983. Carbon dioxide and agricultural yield: An assemblage and analysis of 430 prior observations. Agron. J. 75:779-788.

Kramer, P.J. 1981. Carbon dioxide concentration, photosynthesis and dry matter production. Bioscience 3:29-33.

Krapp, A., B., Hoffman, C., Schafër, and M. Stitt. 1993. Regulation of the expression of rbcS and other photosynthetic genes by carbohydrates: A mechanism of the sink regulation of photosynthesis. Plant J. $3: 817: 828$

Krause, G.H. and E. Weis. 1991. Chlorophyll fluorescence and photosynthesis: The basics. Annu. Rev. Plant Physiol. Plant Mol. Biol.
42:313-349

Ozbun, J.L., J.S. Hawker, E. Greenberg, C. Lammel, J. Preiss, and E.Y.C. Lee. 1973. Starch synthase, phosphorylase, ADP glucose pyrophosphorylase and UDP glucose pyrophosphorylase in developing maize kernels. Plant Physiol. 51:1-5.

Powles, S.B. 1984. Photoinhibition of photosynthesis induced by visible light. Annu. Rev. Plant. Physiol. 35:15-44.

Sage, R.F. 1990. A model describing the regulation of ribulose-1,5bisphosphate carboxylase, electron transport, and triose phosphate use in response to light intensity and $\mathrm{CO}_{2}$ in $\mathrm{C}_{3}$ plants. Plant Physiol. 94:1728-1734.

Sawada, S., Y. Hasegawa, M. Kasai, and M. Sasaki. 1989. Photosynthetic electron transport and carbon metabolism during altered source/ sink balance in single-rooted soybean leaves. Plant Cell Physiol. 30:691-698.

Stitt, M. 1991. Rising $\mathrm{CO}_{2}$ levels and their potential significance for carbon flow in photosynthetic cells. Plant Cell Environ. 14:741-762.

Strasser, R.J., A. Srivastava, and Govindjee. 1995. Polyphasic chlorophyll $a$ fluorescence transient in plants and cyanobacteria. Photochem. Photobiol. 61:32-42.

Stutte, G.W., N.C. Yorio, and R.M. Wheeler. 1996. Interacting effects of photoperiod and photosynthetic photon flux on net carbon assimilation and starch accumulation in potato leaves. J. Amer. Soc. Hort. Sci. 121:264-268.

Topa, M.A. and M. Cheeseman. 1992. Effects of root hypoxia and a low P supply on relative growth, carbon dioxide exchange rates and carbon partitioning in Pinus serotina seedlings. Physiol. Plant. 86:136-144. van Oosten, J.J. and R.T. Besford. 1994. Sugar feeding mimics effect of acclimation to high $\mathrm{CO}_{2}$ - rapid down regulation of Rubisco small subunit transcripts but not of the large subunit transcripts. J. Plant. Physiol. 143:306-312.

van Oosten, J.J. and R.T. Besford. 1995. Some relationships between the gas exchange, biochemistry and molecular biology of photosynthesis during leaf development of tomato plants after transfer to different carbon dioxide concentrations. Plant Cell Environ. 18:1253-1266.

Vezina, F., M.J. Trudel, and A. Gosselin. 1991. Influence du mode d'utilisation de l'éclairage d'appoint sur la productivité et la physiologie de la tomate de serre. Can. J. Plant. Sci. 71:923-932.

von Caemmerer S. and G.D. Farquhar. 1981. Some relationships between the biochemistry of photosynthesis and the gas exchange of leaves. Planta 153:376-387.

Yelle, S., R.C. Beeson, M.J. Trudel, and A. Gosselin. 1989a. Acclimation of two tomato species to high atmospheric $\mathrm{CO}_{2}$. I. Sugar and starch concentrations. Plant Physiol. 90:1465-1472.

Yelle, S., R.C. Beeson, M.J. Trudel, and A. Gosselin. 1989b. Acclimation of two tomato species to high atmospheric $\mathrm{CO}_{2}$. II. Ribulose-1,5bisphosphate carboxylase/oxygenase and phosphoenolpyruvate carboxylase. Plant Physiol. 90:1473-1477. 